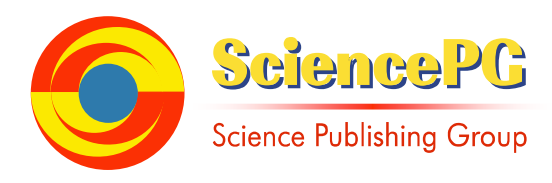

\title{
Assessment of quality of life and fatigue among haemodialysis patients
}

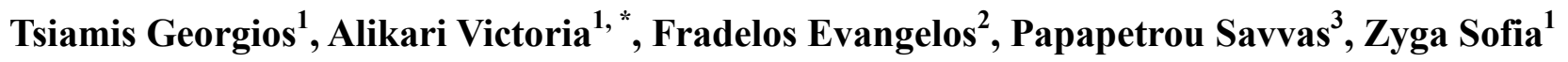 \\ ${ }^{1}$ Department of Nursing, University of Peloponnese, Sparta, Greece \\ ${ }^{2}$ State Mental Hospital of Attica "Daphne", Athens, Greece \\ ${ }^{3}$ Dr of Social Psychology, Educator of Nursing Department, University of Peloponnese, Sparta, Greece
}

\author{
Email address: \\ tsmgeorge@gmail.com (Tsiamis G. ), vicalikari@gmail.com (Alikari V. ), evagelosfradelos@hotmail.com (Fradelos E. ), \\ spapapetrou@yahoo.com (Papapetrou S.), zygas@uop.gr (Zyga S.)
}

\section{To cite this article:}

Tsiamis Georgios, Alikari Victoria, Fradelos Evangelos, Papapetrou Savvas, Zyga Sofia. Assessment of Quality of Life and Fatigue among Haemodialysis Patients. American Journal of Nursing Science. Special Issue: Mental Health Care: Aspects, Challenges and Perspectives. Vol. 4, No. 2-1, 2015, pp. 66-73. doi: 10.11648/j.ajns.s.2015040201.22

\begin{abstract}
Fatigue is one of the most common symptoms of haemodialysis patients and is associated with poor quality of life. Purpose: To investigate the levels of fatigue and its correlation with quality of life of haemodialysis patients. Results: Of the 134 haemodialysis patients, the majority of patients $(52,9 \%)$ seemed to have low rates of fatigue $(10<$ FAS $<=20)$. However, $15 \%$ of these patients seemed to appear high to very high levels of fatigue $(30<\mathrm{FAS}<=50)$. Studying the quality of life of these patients we can observe a correlation between fatigue and quality of life. In particular, patients who experience higher rates of fatigue seem to have worse quality of life (MVQOLI total score 2.90) than those experiencing lower rates of fatigue (MVOQLI total score 3.67) $(\mathrm{p}<0,005)$. Conclusions: The analysis of the results enable us to understand the correlation between fatigue and quality of life among haemodialysis patients with ESRD and the importance of prevention, diagnosis and treatment of fatigue in order to optimize the quality of life in dialysis patients with ESRD.
\end{abstract}

Keywords: Fatigue, Quality of Life, Chronic Kidney Disease, Haemodialysis, End Stage Renal Disease

\section{Introduction}

According to National Kidney Foundation, End Stage Renal Disease (ESRD) is a global health problem while its prevalence in the United States is increasing [1].The number of patients undergoing haemodialysis (HD) has increased from approximately 10.000 in 1973 to 615.899 in 2011 [2].

ESRD can cause not only disorders of basic functions of the organization but also leads to deeper overturn of the emotional, social and economic balance of the individual and its family [3]. Despite the increase of survival of patients with ESRD, complications of the disease or its treatment, such as cardiovascular problems, amyloidosis and malnutrition, are still problems which must be addressed. The survival of HD patients is related to the adequacy of $\mathrm{HD}$, the frequency but not with duration of dialysis session $[4,5,6]$.

Several studies indicate that the quality of life (QoL) of HD patients depends on the social and economic structure of each country, patient's age, sex, education level and worldview. Also, factors such as early referral to the doctor, regular monitoring, the basic disease or concomitant diseases as well as factors related to the method of treatment, affect the QoL of the patient. Significant impact on QoL has, also, the place where treatment is carried out (at home or in hospital) $[7,8,9]$.

Fatigue is one of the most common symptoms of haemodialysis patients and is associated with poor quality of life $[10,11,12]$. The concept of fatigue is unclear while it is too difficult to be defined and assessed, qualitatively and quantitatively. Usually, the term "fatigue" includes several components, such as reduced physical and mental function, decreased energy and performances lower than expected [13].

The prevalence of fatigue ranges from $60 \%$ - 97\% among patients on long-term renal replacement therapy [14]. The significance of fatigue among patients with renal failure is underlined by the fact that $94 \%$ of these patients were keen to undergo more dialysis sessions, if there was a possibility of such an increase in the level of their energy [15]. The level of fatigue among HD patients is one of the highest of all chronic 
patients [16] including those with severe depression [17] ,cancer patients undergoing chemotherapy [18], and patients with lupus [19]. HD patients are sufficiently similar to those suffering from chronic fatigue syndrome, since they have generalized weakness, [20], decreased tolerance in exercise [21], and sleep disorders [22]. These symptoms lead to a sense of "lack of energy" [23]. Moreover, the majority of HD patients complain about various "non-specific" symptoms are very often considered by health professionals as "irrelevant" to the fatigue. However, if these "irrelevant" symptoms could be observed from the view of a "syndrome", it is likely that the final diagnosis and treatment of symptoms would be very different [24].

Despite the great significance of fatigue for HD patients, health professionals are unaware of both the existence and severity of fatigue. For this reason, diagnosis of fatigue is important in order to identify and treat the causes of fatigue. Diagnosis of fatigue can be difficult since the recovery from fatigue shows great variability between patients [25].

The purpose of this study was to investigate and correlate the levels of fatigue and quality of life among haemodialysis patients.

\section{Materials and Methods}

A sample of 134 patients undergoing haemodialysis, was recruited from dialysis units in the broader area of Athens and province. Selection criteria included were to be at least 18 years old or more, have the ability to communicate in Greek, they must have been diagnosed with end-stage renal disease and they must had satisfying level of cooperation and perceived ability. All valid data was entered into a spreadsheet format, and analyses were performed using Statistical Package for Social Sciences, version 20.0. The psychometric tools which were used in the study are presented below.

\subsection{Instruments}

Apart from the questionnaire with socio-demographic characteristics of the patients, two questionnaires were distributed to the participants:

The Missoula-VITAS Quality of Life Index -15 (MVQOLI -15) scale: The Missoula-VITAS Quality of Life Index (MVQOLI) is an assessment tool that gathers information about the QoL of patients during an advanced disease. The Greek version includes 15 questions of the English original. The questions are general. Answers use a five-point scale (Likert), so that the lowest score indicates the least desirable state and vice versa. The questionnaire consists of five dimensions (symptoms, function, interpersonal, well-being, transcendent) and overall quality of life. It is designed specifically to assess the personal experience of each patient in each of these dimensions or domains of QoL. The dimension with negative scores, affect negatively QoL. The dimension with positive scores, affect positively QoL [26].

Each dimension give us information about : (a) Assessment (A) - of perceived circumstance) (b) Satisfaction (S) - of the status or acceptance of an actual circumstance (c) Importance (the degree to which a given dimension has an impact on the overall quality of life).The MVQOLI items are scored as follows: Assessment: -2 to +2 , Satisfaction: -4 to +4 , Importance: 1 to 5. The score of Assessment and Satisfaction can range from -6 to +6 . The sum of Assessment and Satisfaction is multiplied by Importance and the result is the overall impact of the dimension on QoL. The internal validity of the Greek version of the questionnaire was satisfactory with Cronbach's alpha 0.74. [27]

The «Fatigue Assessment Scale (FAS)». This questionnaire investigates and evaluates the ability of the patient to cope in different activities. It consists of ten questions with which the incidence of fatigue is examined. The five of them related to fatigue and half mental fatigue. The 5-point rating scale varies from $1=$ never, $2=$ Sometimes; $3=$ Regularly; $4=$ Often and 5 $=$ Always. The total score comes out adding the score of each question. Score on the FAS can range from 10 to 50 [28]. However, this questionnaire is considered as one-dimensional and, therefore, we can assess only a total score.

\subsection{Ethics}

To conduct this research, the safety of the material was preserved, anonymity of participants was registered and the results obtained were used solely for the purposes of this investigation. Approval from the Department of Nephrology Group Centers was ensured.

\section{Results}

The demographic structure of the sample are presented in Table 1.

Regarding the measurement of fatigue levels, the whole picture of the subjects is depicted in Table 2. Of the 134 patients undergoing HD, it seemed that their ability to cope, mentally and physically, with different activities, and to concentrate during an activity is very limited at $0.7 \%$. This percentage gathers the evaluative category "Never." Also, rate of 52.2\% answered "sometimes", rate of $32.8 \%$ answered "regularly", $12.7 \%$ answered "often" and 1.5\% answered "always".

It is worth noting that men compared to women consider, in a higher proportion their ability has been reduced - in all assed categories - as patients cope in all mentally and physically activities, and to concentrate enough during activities. Specifically, $81.4 \%$ of those who answered "sometimes" were men and 18.6\% women. Moreover, 57.6\% of men and $37.1 \%$ of women answered "sometimes» (Tablet 3). Should be noted that they precede up to $100 \%$ of the evaluative categories "always" and "never."

The average total score of patients in FAS was 22,08. Regarding the evaluation of fatigue assessment indicated that the $52,9 \%$ of the patients exhibits a fatigue rate of $10-20$ on the scale FAS. Regarding the variable of gender, it is worth noting that the average total score for women is slightly higher $(0.19 \% 0)$ than men $(22.22$ versus 22,03$)(\mathrm{p}<0.005)$. Scores distribution of FAS is shown in Table 4. 
Table 1. Demographic characteristics of the sample

\begin{tabular}{|c|c|c|c|c|}
\hline & Frequency & Percent \% & Valid percent & Cumulative Percent \\
\hline \multicolumn{5}{|l|}{ Sex } \\
\hline Men & 99 & 73,9 & 73,9 & 73,9 \\
\hline Women & 35 & 26,1 & 26,1 & 100,0 \\
\hline Total & 134 & 100,0 & 100,0 & \\
\hline \multicolumn{5}{|l|}{ Age } \\
\hline$<30$ & 3 & 2,2 & 2,3 & 2,3 \\
\hline $31-40$ & 7 & 5,2 & 5,3 & 7,5 \\
\hline $41-50$ & 21 & 15,7 & 15,8 & 23,3 \\
\hline $51-60$ & 31 & 23,1 & 23,3 & 46,6 \\
\hline $61-70$ & 43 & 32,1 & 32,3 & 78,9 \\
\hline $71-80$ & 22 & 16,4 & 16,5 & 95,5 \\
\hline $81>$ & 6 & 4,5 & 4,5 & 100,0 \\
\hline Subtotal & 133 & 99,3 & 100,0 & \\
\hline Not answer & 1 & ,7 & & \\
\hline Total & 134 & 100,0 & & \\
\hline \multicolumn{5}{|l|}{ Educational Level } \\
\hline Primary school & 38 & 28,4 & 28,6 & 28,6 \\
\hline Secondary school & 27 & 20,1 & 20,3 & 48,9 \\
\hline High school & 37 & 27,6 & 27,8 & 76,7 \\
\hline University & 27 & 20,1 & 20,3 & 97,0 \\
\hline Master degree & 4 & 3,0 & 3,0 & 100,0 \\
\hline Subtotal & 133 & 99,3 & 100,0 & \\
\hline Not answer & 1 & ,7 & & \\
\hline Total & 134 & 100,0 & & \\
\hline \multicolumn{5}{|l|}{ Marital Status } \\
\hline Unmarried & 25 & 18,7 & 18,7 & 18,7 \\
\hline Married & 89 & 66,4 & 66,4 & 85,1 \\
\hline Divorced & 11 & 8,2 & 8,2 & 93,3 \\
\hline Widowed & 9 & 6,7 & 6,7 & 100,0 \\
\hline Total & 134 & 100,0 & 100,0 & \\
\hline \multicolumn{5}{|l|}{ Occupation } \\
\hline Unemployed & 4 & 3,0 & 3,0 & 3,0 \\
\hline Collar employees & 9 & 6,7 & 6,8 & 9,8 \\
\hline Civil servants & 6 & 4,5 & 4,5 & 14,3 \\
\hline Freelancers & 9 & 6,7 & 6,8 & 21,1 \\
\hline Household & 19 & 14,2 & 14,3 & 35,3 \\
\hline Retired & 85 & 63,4 & 63,9 & 99,2 \\
\hline Student & 1 & ,7 & ,8 & 100,0 \\
\hline Subtotal & 133 & 99,3 & 100,0 & \\
\hline Not answer & 1 & ,7 & & \\
\hline Total & 134 & 100,0 & & \\
\hline
\end{tabular}

Table 2. Fatigue Assessment Scale - FAS (overall)

\begin{tabular}{llllll}
\hline & & Frequency & Percent \% & Valid percent & Cumulative Percent \\
\hline Never & 1 & 1 &, 7 & 7 & 7 \\
Sometimes & 2 & 70 & 52,2 & 52,2 & 53,0 \\
Regularly & 3 & 44 & 32,8 & 32,8 & 85,8 \\
Often & 4 & 17 & 12,7 & 12,7 & 98,5 \\
Always & 5 & 2 & 1,5 & 1,5 & 100,0 \\
Total & & 134 & 100,0 & 100,0 & \\
\hline
\end{tabular}

Table 3. FATIGUE ASSESSMENT SCALE-FAS (Overall)

\begin{tabular}{|c|c|c|c|c|c|c|c|c|c|c|}
\hline & & \multicolumn{3}{|c|}{ Men } & \multicolumn{3}{|c|}{ Women } & \multicolumn{2}{|c|}{ Total } & \multirow[b]{2}{*}{$\% * *$} \\
\hline & & $\mathbf{N}$ & $\% *$ & $\%$ \%* & $\mathbf{N}$ & $\% *$ & $\%$ \%* & $\mathbf{N}$ & $\% *$ & \\
\hline Never & 1 & - & - & - & 1 & 100 & 2,9 & 1 & 100 & 0,7 \\
\hline Sometimes & 2 & 57 & 81,4 & 57,6 & 13 & 18,6 & 37,1 & 70 & 100 & 52,2 \\
\hline Regularly & 3 & 27 & 61,4 & 27,3 & 17 & 38,6 & 48,6 & 44 & 100 & 32,8 \\
\hline Often & 4 & 13 & 76,5 & 13,1 & 4 & 23,5 & 11,4 & 17 & 100 & 12,7 \\
\hline Always & 5 & 2 & 100 & 2 & - & - & - & 2 & 100 & 1,5 \\
\hline Total & & 99 & 73,9 & 100 & 35 & 26,1 & 100 & 134 & & 100 \\
\hline
\end{tabular}

Not answer $0, \mathrm{P}<0,05$
* column represents the evaluative category

** column represents sex

Table 4. Distribution of patients in Fatigue Assessment Scale

\begin{tabular}{llll}
\hline & Frequency & Percent $\%$ & Cumulative Percent \\
\hline $10<$ FAS $<=20$ & 71 & 52,9 & 52,9 \\
$20<$ FAS $<=30$ & 43 & 32,1 & 85,0 \\
$30<$ FAS $<=40$ & 18 & 13,5 & 95,5 \\
$40<$ FAS $<=50$ & 2 & 1,5 & 100,0 \\
Total & 134 & 100,0 & \\
\hline
\end{tabular}

$\mathrm{P}<0,05$ 
As far as the final results on the MVQOLI-15 scale, the answers to each of the individual factors are presented in

Table 5.

Table 5. Final results of the individual factors on the scale MVOOLI-15

\begin{tabular}{|c|c|c|c|c|}
\hline \multicolumn{5}{|l|}{ Overall Quality of Life } \\
\hline & Frequency & Percent $\%$ & Valid percent & Cumulative Percent \\
\hline Very poor & 2 & 1,5 & 1,5 & 1,5 \\
\hline Poor & 9 & 6,7 & 6,7 & 8,2 \\
\hline Moderate & 51 & 38,1 & 38,1 & 46,3 \\
\hline good & 56 & 41,8 & 41,8 & 88,1 \\
\hline Very good & 16 & 11,9 & 11,9 & 100,0 \\
\hline Total & 134 & 100,0 & 100,0 & \\
\hline \multicolumn{5}{|l|}{ Symptom (S) } \\
\hline Strongly disagree & 72 & 53,7 & 53,7 & 53,7 \\
\hline Disagree & 3 & 2,2 & 2,2 & 56,0 \\
\hline Neither agree nor disagree & 15 & 11,2 & 11,2 & 67,2 \\
\hline Strongly agree & 22 & 16,4 & 16,4 & 83,6 \\
\hline Agree & 22 & 16,4 & 16,4 & 100,0 \\
\hline Total & 134 & 100,0 & 100,0 & \\
\hline \multicolumn{5}{|l|}{ Function (F) } \\
\hline Strongly disagree & 9 & 6,7 & 6,7 & 6,7 \\
\hline Neither agree nor disagree & 19 & 14,2 & 14,2 & 43,3 \\
\hline Strongly agree & 51 & 38,1 & 38,1 & 81,3 \\
\hline Agree & 25 & 18,7 & 18,7 & 100,0 \\
\hline Total & 134 & 100,0 & 100,0 & \\
\hline \multicolumn{5}{|l|}{ Interpersonal (IP) } \\
\hline Strongly disagree & 6 & 4,5 & 4,5 & 4,5 \\
\hline Disagree & 10 & 7,5 & 7,5 & 11,9 \\
\hline Neither agree nor disagree & 24 & 17,9 & 17,9 & 29,9 \\
\hline Strongly agree & 74 & 55,2 & 55,2 & 85,1 \\
\hline Agree & 20 & 14,9 & 14,9 & 100,0 \\
\hline Total & 134 & 100,0 & 100,0 & \\
\hline \multicolumn{5}{|l|}{ Well-Being (WB) } \\
\hline Strongly disagree & 77 & 57,5 & 57,5 & 57,5 \\
\hline Disagree & 23 & 17,2 & 17,2 & 74,6 \\
\hline Neither agree nor disagree & 14 & 10,4 & 10,4 & 85,1 \\
\hline Total & 134 & 100,0 & 100,0 & \\
\hline \multicolumn{5}{|l|}{ Transcendent $(\mathrm{T})$} \\
\hline Strongly disagree & 66 & 49,3 & 49,3 & 49,3 \\
\hline Disagree & 33 & 24,6 & 24,6 & 73,9 \\
\hline Neither agree nor disagree & 10 & 7,5 & 7,5 & 81,3 \\
\hline Strongly agree & 10 & 7,5 & 7,5 & 88,8 \\
\hline Agree & 15 & 11,2 & 11,2 & 100,0 \\
\hline Total & 134 & 100,0 & 100,0 & \\
\hline
\end{tabular}

The patients' mean score for the dimensions of MVQOL-15 is shown in Table 6.

Table 6. Score of each dimension in MVQOLI-15

\begin{tabular}{llll}
\hline & Men & Women & Total \\
\hline Overall QoL & 3,63 & 3,34 & 3,55 \\
Symptoms & 5,79 & 6,42 & 5,96 \\
Function & 4,04 & 4,68 & 4,20 \\
Interpersonal & 5,64 & 6,91 & 5,97 \\
Well-being & $-10,68$ & $-8,54$ & $-10,12$ \\
Transcendent & $-9,94$ & $-9,57$ & $-9,85$ \\
Total score & 14,48 & 14,99 & 14,63 \\
\hline
\end{tabular}

$\mathrm{P}<0,00$

In order to study QoL of 134 patients compared with fatigue, we divided the patients into two groups. The first group consisted of patients with a score less than or equal to $30(\mathrm{~N}=$
114) in FAS while the second group consisted of patients with a score greater than 30 in FAS $(\mathrm{N}=20)(\mathrm{p}<0.005)$. (Table 7)

Table 7. Distinguishing patients in Groups.

\begin{tabular}{lll}
\hline & N & Percentage \% \\
\hline FAS $<=30($ Group 1) & 114 & $85,08 \%$ \\
FAS $>30($ Group 2) & 20 & $14,92 \%$ \\
Total & 134 & $100,0 \%$ \\
\hline
\end{tabular}

$\mathrm{p}<0,005$

The results of correlation between fatigue and the dimensions of QoL are presented in Table 8. According to Table 8, the patients with low fatigue rates (Group 1) appear to exhibit higher score in dimensions of MVQOL-15 compared to those who exhibit high fatigue rates (Group 2). The Group 1 shows a lower score compared to Group 2 in the dimension of 
transcendent. The total score of all the dimensions was 14.63 .

Table 8. Comparison of each dimension between the two groups

\begin{tabular}{lll}
\hline & Group 1 & Group 2 \\
\hline Overall quality of life & 3,67 & 2,90 \\
Symptoms & 6,65 & 2,00 \\
Function & 5,00 & $-0,35$ \\
Interpersonal & 6,33 & 3,95 \\
Well-being & $-9,56$ & $-13,35$ \\
Transcendent & $-11,65$ & 0,45 \\
Total score & 14,67 & 14,27 \\
\hline
\end{tabular}

$\mathrm{P}<0,005$

\section{Discussion}

In this study we attempted to investigate the levels of fatigue, quality of life of HD patients and to correlate these two parameters. 134 patients were enrolled. 35 were women and 99 men. The majority of patients $(55.6 \%)$ belonged to the age group 51-70. The majority of patients $(63.9 \%)$ were retired. The average total score of patients in FAS questionnaire was 22,08 while in MVQOL-15 was 14,63 .Regarding the gender, women had slightly higher $(0.19 \%$ $0)$ fatigue rate than men.

\subsection{Fatigue}

According to the findings of our study and the literature, fatigue is a complex phenomenon which negatively affects health-related QoL of HD patients [29,30].

Generally, HD patients of our study show to have low to moderate levels of fatigue. In the study of Horigan et al, fatigue seems to occur at high rates $(60 \%-97 \%$ of HD patients) [31] .The rates are higher than the rates of our study which showed that $47.1 \%$ have moderate to very high stress levels while $52.9 \%$ of patients showing low fatigue rates. The low percentage of moderate and high fatigue and the high percentage of low fatigue in our study is probably due to the fact that the majority of patients were non-diabetic, below 70 years and men $(73.9 \%)$. Regarding the last feature we should note that gender seems to influence the level of fatigue among HD patients. In our study, women had higher rate of fatigue in relation to men. Other studies, also, indicate that women suffer from higher levels of fatigue than men [32,33,34].

\subsection{Quality of Life}

In Greece, assessment studies of health-related QoL of HD patients are minimal [27, 35,36,]. The MVQOL questionnaire has been used again in Greek HD patients by Theofilou et al [27]. The results of this study tend to be similar to those of our study. The total score of MVQOL-15 QOL scale of the patients was 17.36 while in our study was 14.63 . The rating in the study of Theofilou for the dimension of interpersonal relations was 16.26 , more than any other dimension. The same applies in our study where the score for the dimension of interpersonal relations was 5.97, the highest of all dimensions. $(p<0,005)$. Therefore, the dimension of interpersonal relationships is the dimension that affects positively in most the QoL of HD patients. This could be attributed to the fact that these patients are missing from their house three times a week, they are around health care professionals and nurses so they feel 1 they can make social relationships. In addition, $66,4 \%$ of the sample was married. That way perhaps it is explained that the subscale of interpersonal relationships positively affect QOL. Dialysis patients, like other chronically patients, require a great deal of social support. The degree of family support has been described as an important predictor of the QoL among other HD patients [37]. Typically, the spouse is the first line of support for the married patient; compared to family and friends for non-married patients. However, being married and living with a chronic disease may negatively impact on marital life. The dimensions of function (score: 4.26) and symptoms (score: 3.83 ) follow in the study of Theofilou while in our study the dimensions of symptoms (score: 5,96 ) and of function follow (score: 4,2 ) ( $\mathrm{p}<0,005)$. We conclude, therefore, that in both studies the dimensions of interpersonal relationships, symptoms and function positively affect QoL of HD patients. The dimension that affects, in both studies, more negatively the QoL of HD patients from all dimensions, is that of well-being. Regarding the dimension of transcendent we found differences between the two studies. Specifically, in our study the dimension of transcendent (score: $-9,85$ ) negatively affects the QoL of HD patients whereas in the study of Theofilou affects positively (score: 6,75). As far as the dimension of the overall QoL, score was not significantly different between the two studies $(3,55$ for our study and 3.25 for the other study).

Gender is a factor which affects QoL in general population and HD patients as well [38]. Females have poor QoL as compared to male patients. In our study women showed higher scores in interpersonal relationships. In contrast, in the study of Anees females have poor QOL as compared to male patients in social relationship dimension [32].

\subsection{Correlation of Fatigue and Quality of Life}

To study the correlation of fatigue with the QoL of 134 patients, we divided patients into two groups. The first group consisted of patients with a score less than or equal to $30(\mathrm{~N}=$ 114) in FAS while the second group consisted of patients with a score greater than 30 in FAS. The results showed that patients with low fatigue levels seem to enjoy better QoL compared to those who have high fatigue levels.

Considering the burden of the symptoms that are daily experienced by patients undergoing HD (weakness, nausea, cramps, itching, pain) $[39,40]$ correlated the levels of fatigue with the subscale of symptoms. The dimension of symptoms affecting more positive quality of life for patients who are experiencing lower levels of fatigue (Group 1score: 6,65) compared to those who are experiencing higher levels of fatigue (Group 2score: 2) $(p<0,005)$. Jhamb et al [14] reported that HD patients with high levels of fatigue couldn't manage physical symptoms such as pain, while Finnegan JJ\& Thomas [41] indicating that fatigue, poor body energy, and natural changes of the body (such as placing a central venous catheter), changes in normal body weight, scarves may 
determent an important role for maintain confidence and self-esteem.

The dimensions of interpersonal relationships and function are following, which, also, have positive influence on the QoL of patients of Group 1 opposed to Group 2. More specific interpersonal relationships doesn't seem to influence QoL negatively in both groups (Group 1 score 6,33, Group 2 score $3,95(p<0,005)$. Function influence in a negative way the QoL in group 2 (Group 1 score:5, Group 2 score: -0,35 $(\mathrm{p}<0,005)$. As it was expected, considering that higher levels of fatigue are reducing individuals capacity to taking care of himself. Similar results were reported by Brunier and Graydon [42] who found that fatigue is negatively correlated with activity levels of HD patients while other researchers have negatively linked fatigue with its restrictive role and the natural functions.[14, 23,33]. In another qualitative study patients correlated physical fatigue with side effects of dialysis [44] while in another study the reduced function influenced the patients' ability to cope with daily activities [45]. Well-being is negatively affected in both groups. (Group score 1 : $-9,56$, Group score $2 ;-13,35)(p<0,005)$. Perhaps the low levels of well-being are related to the existing anemia of HD patients, malnutrition, inadequacy of clearance, secondary hyperparathyroidism, uremia, sleep disorders and diet restrictions. On the dimension of transcendent we found that this affects very negatively the QoL of group 1 and few positive the QoL of Group 2. This finding may be explained by the different views between the two groups about the meaning and value of life. Specifically, people with high levels of fatigue believe, to a greater proportion, that their life has meaning after accession the haemodialysis than before accession. This is due to the fact that people who experience more fatigue give value to the meaning of life perhaps because they have come closer to death. Addressing of their own mortality may have been a factor that led patients to an internal evaluation and caused them to see their health from a new perspective of finding a balance in their relationships and improving of self-care. Similar finding was mentioned by Walton [46] on the importance of hope of HD patients while other studies emphasize the value of transcendent $[47,48]$.

As far as the dimension of the overall QoL, we found that patients of Group 1 have a better QoL (score 3,67) compared to patients of Group 2 (score 2,90).

Regarding the total score, if we compare the total score of both groups in Missoula- VITAS Quality of Life Index (MVQOLI) scale, we can see that patients of Group 1 have higher total score of the scale compared to patients of Group 2. The dimensions, in whole, seem to affect more positively patients of Group 1 compared to patients of Group 2.

On the basis of these arguments we result that the need for identification and evaluation of fatigue of patients undergoing haemodialysis is vital for the QoL. The complexity of pathogenesis, the lack of effective methods of measuring and the non-recognition by health professionals makes the development of effective intervention methods difficult.[14]

\section{Recommendations}

Physical exercise, use of erythropoietin and L- carnitine have been successfully used to relieve fatigue in patients undergoing haemodialysis [49]. However, due to the complexity of fatigue, health professionals should adopt a comprehensive approach.

The first step in dealing with fatigue is to recognize it as a symptom and measure. Early treatment of fatigue in primary health care can prevent the development of it [31].Healthcare professionals should be trained in order to be able to recognize and address the symptom of fatigue. Furthermore, there is a great need to develop improved fatigue assessment methods and to investigate the role of other factors contributing to fatigue. An assessment of these factors can identify potential targets to which we can intervene therapeutically. To improve the QoL of HD patients, we need to identify the techniques which patients use to manage their fatigue. There remains a critical lack of knowledge regarding the experience and self-management of fatigue in hemodialysis patients;

\section{Conclusions}

Until now, the approach of fatigue in HD patients as a separate symptom failed to reduce the feeling of fatigue [50]. Therefore, the observation of points and symptoms of fatigue with an holistic approach can help health professionals and scientists to address the problem. Such an approach would be difficult, considering the diversity of these symptoms, but not impossible, and can provide great benefits to the QoL of HD patients.

\section{Limitations}

The results would be more reliable and possibly differentiated if the sample size was bigger and the geographical distribution wider. Moreover, the fact that the questionnaires were completed during the HD session, presence of medical and nursing staff and other patients, may affect the objectivity of responses. Moreover, the Fatigue Assessment Scale is unidimensional and therefore does not calculate the physical and mental fatigue separately.

\section{References}

[1] K/DOQI clinical practice guidelines for chronic kidney disease: evaluation, classification, and stratification. National Kidney Foundation. Am J Kidney Dis. 2002;39(2 Suppl 1):S1.

[2] http://www.uptodate.com/contents/epidemiology-of-chronic-k idney-disease

[3] R. Foley, B. Curtis , P. Parfrey, "Erythropoietin Therapy, Hemoglobin Targets, and Quality of Life in Healthy Hemodialysis Patients: A Randomized Trial," CJASN 2009 vol. 4 726-733.

[4] AR. Qureshi , A. Alvestrand , C. Divino-Filho , A. Gutierrez, O. Heimbürger, B. Lindholm, J. Bergström, "Inflammation, malnutrition, and cardiac disease as predictors of mortality in hemodialysis patients," J Am Soc Nephrol. 2002 Jan; 13 Suppl 1:S28-36. 
[5] C. Combe , P. Chauveau , M. Laville , D. Fouque , Azar R, Cano N, Canaud B, Roth H, Leverve X, Aparicio M. Influence of nutritional factors and hemodialysis adequacy on the survival of 1,610 French patients. Am J Kidney Dis. 2001 Jan;37(1 Suppl 2):S81-8.

[6] J. Oliva , L. Roa, L. Alfonso , S. Garrido, M. Salgueira, A. Palma, A. José, "Milán, Guillermo Martín-Reyes. Survival and factors predicting mortality in hemodialysis patients over 75 years old," J Nephrol 2013; 26(1): 129 - 135.

[7] N. Kutner, R. Zhang, H. Barnhart, A. Collins, "Health status and quality of life reported by incident patients after 1 year on haemodialysis or peritoneal dialysis," Nephrol Dial Transplant. 2005 Oct;20 (10), pp. 2159-67.

[8] A. Untas , J. Thumma , N. Rascle , H. Rayner, D. Mapes , A. Lopes , S. Fukuhara, T. Akizawa , H. Morgenstern , B. Robinson, R. Pisoni , C. Combe, "The associations of social support and other psychosocial factors with mortality and quality of life in the dialysis outcomes and practice patterns study,” Clin J Am Soc Nephrol. 2011 Jan;6(1):142-52.

[9] S. Ho , C. Ho , N. Norshazwani , K. Teoh , M. Ismail , M. Jaafar ,S. Das, "Perception of quality of life amongst end stage renal failure patients undergoing haemodialysis," Clin Ter. 2013;164(6):499-505.

[10] R. Eğlence, N. Karataş, S. Taşci, "The effect of acupressure on the level of fatigue in hemodialysis patients," Altern Ther Health Med. 2013 Nov-Dec;19(6):23-31.

[11] Mollaoglou, "Fatigue in People Undergoing Hemodialysis," Dialysis \& Transplantation, 2009 Vol 38, Issue 6.

[12] W.Chang, K. K. Hung , J.Huang , K.Wu , T.Tsai, "Chronic fatigue in long-term peritoneal dialysis patients," Am J Nephrol. 2001 Nov-Dec; 21(6):479-85.

[13] L Krupp, "Fatigue," Philadelphia, USA, Butterworth Heinemann, 2003.

[14] M. Jhamb , C. Argyropoulos, J. Steel, L. Plantinga, A.Wu, N. Fink, N. Powe, K. Meyer, and M. Unruh, "Correlates and Outcomes of Fatigue among Incident Dialysis Patients," Clin J Am Soc Nephrol. Nov 2009; 4(11): 1779-1786.

[15] N. Ramkumar , S. Beddhu , P.Eggers , L.Pappas , A. Cheung,"Patient preferences for in-center intense hemodialysis," Haemodial Int 9: 281- 295, 2005.

[16] J.Ware, , Kristin, K., Kosinski, S. M., and B.Gandek, (1993). SF-36® Health Survey Manual and Interpretation Guide. Boston, MA: Medical Center, The Health Institute.

[17] L.Yatham, , Y. Lecrubier,R. Fieve, K. Davis, S. Harris, and A.Krishnan, "Quality of life in patients with bipolar I depression: data from 920 patients,"Bipolar Disord.2004, 6, 379-385.

[18] L.Adamsen, M. Quist, C. Anderse, T.Moller, J.H errstedt, D. Kronborg, M. Baadsgaard, K.Vistisen J. Midtgaard, B.Christiansen, M.Stage, M. Kronborg, and M. Rorth, "Effect of a multimodal high intensity exercise intervention in cancer patients undergoing chemotherapy: A randomised controlled trial,” BMJ , 2009339, b3410.

[19] M. Jolly, "How does quality of life of patients with systemic lupus erythematosus compare with that of other common chronic illnesses? J. Rheumatol.2005,32,1706-1708.
[20] K. Johansen, T. Shubert, J. Doyle, B. Soher, G. Sakkas, and J. Kent-Braun, "Muscle atrophy in patients receiving hemodialysis: effects on muscle strength, muscle quality, and physical function,” Kidney Int. 2003, 63, 291-297.

[21] K. Johansen, and P.Painter, "Exercise in individuals with CKD," Am. J. Kidney Dis. 2012, 59, 126-134.

[22] G. Sakkas ,K. Gourgoulianis , C. Karatzaferi , V. Liakopoulos , M. Maridaki M, C.Pastaka, E. Lavdas, B. Soher, S. Dovas , I. Fezoulidis, G.H adjigeorgiou, I. Stefanidis, 'Haemodialysis patients with sleep apnoea syndrome experience increased central adiposity and altered muscular composition and function,” Nephrol. Dial. Transplant.2008, 23, 336-34410.

[23] K. McCann , \& J. Boore, "Fatigue in persons with renal failure who require maintenance haemodialysis," Journal of Advanced Nursing,2000, 32(5), 1132-1142.

[24] G. Sakkas , C. Karatzaferi, "Hemodialysis fatigue: just "simple" fatigue or a syndrome on its own right?," Front Physiol. 2012 Jul 31;3:306.

[25] R. Lindsay, P. Heidenheim, G. Nesrallah, A. Garg, and R. Suri, "Minutes to recovery after a hemodialysis session: a simple health-related quality of life question that is reliable, valid, and sensitive to change,'. Clin. J. Am. Soc. Nephrol. 2006, 1,952-959.

[26] I.Byock, M. Merriman, "Measuring quality of life for patients with terminal illness: the Missoula-VITAS quality of life index," J. Pal. Med. 1998; 12:231-244.

[27] P. Theofilou, A. Aroni, M. Ralli, M. Gouzou, S. Zyga, "Measuring health: related quality of life in hemodialysis patients. Psychometric pro.perties of the Missoula-VITAS Quality of Life Index (MVQOLI-15) in Greece. Health psychology research 2013, vol 1:e17.

[28] H. Michielsen, J. De Vries, L. Guuns Van Heck, "Psychometric qualities of a brief self-rated fatigue measure The Fatigue Assessment Scale," Journal of Psychometric Research 54 (2003) 345-352.

[29] S.Weisbord, L. Fried, , R.Arnold, M. Fine, D. Levenson, R. Peterson, "Prevalence, severity, and importance of physical and emotional symptoms in chronic hemodialysis patients," Journal of the American Society of Nephrology, 2005,16(8), 2487-2494.

[30] A. Jablonski, (2007). Level of symptom relief and the need for palliative care in the hemodialysis population. Journal of Hospice and Palliative Nursing, 9(1), 50-58.

[31] A. Horigan , J. Rocchiccioli , D. Trimm D, "Dialysis and fatigue: implications for nurses--a case study analysis," Medsurg Nurs. 2012;21(3):158-63.

[32] M. Anees, M. Malik, T. Abbasi , Z. Nasir Z Y. Hussain, M. Ibrahim, "Demographic factors affecting quality of life of hemodialysis patients," Pak J Med Sci. 2014 Sep;30(5):1123-7.

[33] D. O' Sullivan , G. McCarthy G, "An exploration of the relationship between fatigue and physical functioning in patients with end stage renal disease receiving haemodialysis," Journal of Clinical Nursing, Volume 16, Issue 11c, pages 276-284, 2007.

[34] H. Liu, "Fatigue and associated factors in hemodialysis patients in Taiwan," Res Nurs Health, 29 (2006), pp. 40-50. 
[35] P. Theofilou, H. Panagiotaki, "Quality of Life in Patients with Chronic Renal Failure: Differences between the Early and Later Years of Current Treatment," NOSILEFTIKI 2010, 49(3) 295-304

[36] P. Theofilou,"Quality of life in end - stage renal disease: a qualitative analysis," Interscientific Health Care (2011) Vol 3, Issue 2, 70-80.

[37] K. Van, S. Duangpaeng, A. Deenan and A. Bonner, "Examining the health-related quality of life of people with end-stage kidney disease living in Hanoi," Vietnam. Renal Society of Australasia Journal, 2012, 8(3), 140-145.

[38] P. Santos , E, Daher , G.Jr Silva , A. Libório, L. Kerr, "Quality of life assessment among haemodialysis patients in a single centre: a 2-year follow-up," Qual Life Res. 2009;18(5):541-546.

[39] C. Almeras, and A. Argiles, "The general picture of uremia. Seminars in Dialysis,” 2009, 22(4), 329-333.

[40] D. Yong, D. A. Kwok, D. Wong, M. Suen, W. Chen, and D.Tse, "Symptom burden and quality of life in end-stage renal disease: a study of 179 patients on dialysis and palliative care," Palliative Medicine, 2009, 23(2), 111-119.

[41] J. Finnegan and J. Thomas, "The Psychosocial Experience of Patients with End-Stage Renal Disease and Its Impact on Quality of Life: Findings from a Needs,'ISRN Nephrol. Article ID 308986,8

[42] G. Brunier,and J .Graydon, "The influence of physical activity on fatigue in patients with ESRD on hemodialysis," ANNA J. 1993 Aug;20(4):457-61; discussion 462, 521.
[43] L. Lee, Chaboyer, Chiang, and Hung, "The fatigue experience of haemodialysis patients in Taiwan," Journal of Clinical Nursing,2007, 16(2), 407-413.

[44] S. Heiwe, N. Clyne, \& M.Dahlgren, "Living with chronic renal failure: patients' experiences of their physical and functional capacity," Physiotherapy Research International,2003, 8(4), 167-177.

[45] J. Walton, "Finding a balance: A grounded theory study of spirituality in hemodialysis," Nephrology Nursing Journal,2002, 29, 447-457.

[46] O. Caspi, M. Koithan, and M.Criddle,, "Alternative medicine or "alternative" patients: A qualitative study of patient-oriented decision making process with respect to complementary and alternative medicin,”. Medical Decision Making,2004, 24, 64-79.

[47] J.Singleton, "Caring for themselves: Facilitators and barriers to women home care workers who are chronically ill following their care plan," Health Care for Women International, 2002,23, 692-702.

[48] P. Gordon, J. Doyle, and K. Johansen , "Postdialysis fatigue is associated with sedentary behavior. Clin. Nephrol. 2011,75, 426-433.

[49] S. Letchmi, S. Das, H. Halim, F. Zakariah, , H. Hassan, S. Mat, and R. Packiavathy, "Fatigue experienced by patients receiving maintenance dialysis in hemodialysis unit,". Nurs. Health Sci .2011, 13, 60-64.

[50] K. Johansen , and P. Painter ,"Exercise in individuals with CKD,” Am. J. Kidney Dis. 2012, 59, 126-13410. 